\title{
Prolonged Infusions of Angiotensin II and Norepinephrine and Blood Pressure, Electrolyte Balance, and Aldos- terone and Cortisol Secretion in Normal Man and in Cirrhosis with Ascites *
}

\author{
Richard P. Ames, $†$ Abraham J. Borkowski, $\ddagger$ Alfred M. Sicinski, $\$$ and \\ JOHN H. LARAGH \| \\ (From the Department of Medicine, College of Physicians \& Surgeons, Columbia University \\ and the Presbyterian Hospital, New York, N. Y.)
}

A series of renal-adrenal interactions involving the pressor peptide angiotensin may control sodium balance and blood pressure in normal man (1). Evidence for this is derived from numerous experiments in man (2-4) and animals (5-17). We propose a mechanism whereby the kidney, when its perfusion is threatened, releases renin. Renin liberates angiotensin from a specific circulating globulin. Angiotensin, in turn, stimulates the secretion of aldosterone by the adrenal cortex. Angiotensin and aldosterone, by increasing arterial pressure and renal sodium retention, help restore renal perfusion, thus compensating the system.

Although it has been demonstrated repeatedly that infused angiotensin stimulates the secretion of aldosterone and causes renal retention of sodium, we do not know if the release of endogenous angiotensin is normally associated with the release of aldosterone. Most of our speculation concerning angiotensin as a trophic hormone for aldosterone is derived from studies of the pathological hypersecretion of aldosterone. Angiotensin is implicated in disorders such as malignant hypertension $(1,2)$ and the edematous states of cirrhosis, nephrosis, and heart failure (18) because they are usually associated with renal damage and hypertension or abnormal renal electrolyte behavior.

\footnotetext{
* Submitted for publication August 19, 1964; accepted March 18, 1965. This work was supported by grants H-1275 and H-5741 from the U. S. Public Health Service and by the Fleitas Fund.

† Fellow of the New York Heart Association.

$\ddagger$ Fellow of the Polachek Foundation.

$\S$ Fellow of the Rockefeller Foundation.

|| Address requests for reprints to Dr. John H. Laragh, Dept. of Medicine, College of Physicians \& Surgeons, Columbia University, New York, N. Y. 10032.
}

If angiotensin plays a major role in the control of aldosterone secretion, 1) it should stimulate aldosterone secretion in nonpressor or mildly pressor doses since most examples of secondary aldosteronism are not accompanied by arterial hypertension ; 2) aldosterone should be stimulated selectively since hyperaldosteronism is not usually accompanied by increased cortisol secretion; and 3) aldosterone stimulation should continue as long as hyperangiotensinemia obtains because the pathological secretion of aldosterone is persistent.

At present we have not shown that angiotensin meets these requirements. In fact, the literature provides both positive and negative opinions for each proposal $(1,3,16-22)$. We have examined the influences of prolonged infusions of angiotensin on arterial pressure, on the selectivity and persistence of the stimulation of aldosterone, and on electrolyte balance. These observations were compared with similar studies using the pressor agent norepinephrine. Our subjects were normal volunteers and patients with cirrhosis and ascites, a disease involving a typical form of secondary aldosteronism.

\section{Methods}

We studied seven normal volunteers and eleven patients with cirrhosis. The diagnosis of cirrhosis was determined from pertinent findings of the history and physical and laboratory examinations. It was confirmed histologically in seven patients. Ten of the patients with cirrhosis had ascites; one had completed a spontaneous diuresis. Because this latter patient (no. 3) was in clinical remission and had corrected the abnormalities of electrolyte and aldosterone metabolism usually associated with ascites formation, she was grouped with the normal subjects. One hypertensive patient with uncomplicated disease of 12 years known duration was also studied. In all instances full explanation of the nature of the study 
was given, and the full cooperation of the subjects was obtained.

The studies were conducted on the metabolism ward where all subjects received a constant daily diet of known electrolyte content. All subjects received the control diet for at least 6 days before study. Normal patients were maintained on either normal or low sodium diets, the electrolyte composition of which is given in Table I.

All subjects received infusions of angiotensin and norepinephrine in $5 \%$ dextrose solution at a rate of approximately $0.5 \mathrm{ml}$ per minute, held constant by a Bowman pump. Sphygmomanometric blood pressures were recorded at 1-hour intervals during the day and 2-hour intervals at night. We have defined pressor infusions as an elevation to $150 / 100$; nonpressor is a minimal elevation in both systolic and diastolic pressure. Throughout the study patients were permitted limited ambulation and lavatory privileges, since infusions were made through a 12-foot tube. Metabolic ward technics and the procedures for the routine analysis of plasma and urinary electrolytes have been described elsewhere (2). Many of our basal aldosterone secretory rates were obtained by 24-hour infusions of $5 \%$ dextrose without added pressor agent.

Aldosterone secretory rates were determined by an isotope dilution technic. 7 or 1, 2, tritium-labeled aldosterone was obtained from the U. S. Public Health Service (SA, 20 and $100 \mu \mathrm{c}$ per $\mu \mathrm{g}$ ). Each batch was checked for purity and stability at monthly intervals by $a$ ) addition

TABLE I

Effect of 8- to 24-hour infusions of angiotensin or norepinephrine on sodium balance and aldosterone and cortisol secretion in normal.subjects



* An interval of several days separated the repeated studies of Subjects 5 to 7 . Five and two weeks of the constant regimen elapsed before the final studies of Subjects 6 and 7.

$\dagger$ Blood pressure measurements are 24-hour means.

$\ddagger$ Infusion less than 24 hours.

$\$$ Excretory rate. 
ANGIOTENSIN, ALDOSTERONE, SODIUM BALANCE, AND BLOOD PRESSURE

TABLE II

Effect of 8-to 24-hour infusions of angiotensin or norepinephrine on sodium balance, and aldosterone and cortisol secretion in patients with cirrhosis and ascites

\begin{tabular}{|c|c|c|c|c|c|c|c|c|c|}
\hline \multirow[b]{2}{*}{ Patients and conditions } & \multirow[b]{2}{*}{ Dose } & \multicolumn{2}{|c|}{ Blood pressure } & \multicolumn{2}{|c|}{$\begin{array}{l}\text { Urinary sodium } \\
\text { excretion }\end{array}$} & \multicolumn{2}{|c|}{$\begin{array}{l}\text { Aldosterone } \\
\text { secretion }\end{array}$} & \multicolumn{2}{|c|}{$\begin{array}{r}\text { Cortisol } \\
\text { secretion }\end{array}$} \\
\hline & & Control & Exp. & Control & $\overline{\text { Exp. }}$ & Control & Exp. & Control & $\overline{\text { Exp. }}$ \\
\hline
\end{tabular}

Diet, 7-18 $\mathrm{mEq}$ sodium, $120 \mathrm{mEq}$ potassium

$10^{*}$
$11^{*}$
12
12
$13^{*}$
$13^{*}$
$13^{*}$ (postshunt)
$14^{*}$
14
15
15
$16^{*}$
$16^{*}$
$16^{*}$
17
18
18
$18^{*}$
19

Angiotensin

dexamethasone, $3 \mathrm{mg}$ daily

$12^{*}$

Diet, $12 \mathrm{mEq}$ sodium, $190 \mathrm{mEq}$ potassium, and dexamethasone, $3 \mathrm{mg}$ daily

17

Diet, 7-18 mEq sodium, $120 \mathrm{mEq}$ potassium

$10^{*}$
12
$13^{*}$
15
$16^{*}$
$17^{*}$
18
19

$\begin{array}{rrr}1.0 & 120 / 60 & 120 / 65 \\ 1.2 & 110 / 65 & 150 / 80 \\ 0.47 & 90 / 60 & 110 / 70 \\ 2.4 & 98 / 65 & 135 / 88 \\ 19.0 & 100 / 60 & 152 / 84 \\ 2.4 & 95 / 65 & 114 / 69 \\ 6.8 & 96 / 66 & 147 / 82 \\ 5.3 & 115 / 80 & 125 / 95 \\ 4.9 & 115 / 80 & 150 / 90 \\ 0.12 & 120 / 70 & 120 / 70 \\ 6.7 & 124 / 60 & 182 / 92 \\ 2.4 & 110 / 70 & 127 / 85 \\ 8.3 & 100 / 70 & 142 / 90 \\ 12.1 & 100 / 60 & 142 / 94 \\ 3.6 & 134 / 76 & 140 / 79 \\ 0.6 & 110 / 60 & 130 / 65 \\ 7.1 & 105 / 55 & 166 / 79 \\ 17.3 & 104 / 60 & 168 / 98 \\ 4.6 & 90 / 60 & 102 / 71\end{array}$

0.3
38
1.8
1.0
0.6
3.8
0.7
25
2.5
0.1
0.6
0.1
0.2
0.3
2.0
0.4
0.4
2.0
0.5

$0.3 \quad 1,560$

$\begin{array}{ll}45 & 157\end{array}$

$8.1 \quad 177$

$\begin{array}{rr}90 & 1,098 \\ 116 & 941\end{array}$

$\begin{array}{rr}116 & 941 \\ 1 & 967\end{array}$

180

2.1

87

0.3

334

$2.8 \quad 1,027$

$37.8,243$

$64 \quad 2,443$

$6.0 \quad 583$

$0.6 \quad 309$

170
501

0.4 $\begin{array}{lrr}2.7 & 97 / 65 & 155 / 89 \\ 4.0 & 124 / 75 & 165 / 85\end{array}$

1.3

270

2.8

536
366

1,058

1,368

108
367

965

772

5.4

12.2

928

439

582

797

1,866

1,846

2,780

1,119
358

$8.1 \quad 13.5$

92
117

6

41
$4.7 \quad 116 / 75 \quad 146 / 85$
Norepinephrine

2.7

$2.8 \quad 723$

1,058

$\begin{array}{rrr}14.8 & 120 / 65 & 160 / 80 \\ 33.0 & 98 / 66 & 146 / 90 \\ 22.2 & 98 / 60 & 145 / 78 \\ 12.9 & 120 / 60 & 149 / 63 \\ 39.4 & 120 / 75 & 187 / 76 \\ 33.3 & 110 / 72 & 132 / 80 \\ 8.3 & 116 / 60 & 148 / 73 \\ 19.7 & 104 / 60 & 168 / 72 \\ 14.3 & 90 / 60 & 143 / 94\end{array}$

0.3
0.3
0.7
0.4
0.3
0.6
3.0
0.7
0.8

1,368
487
465
1,089
2,165
649
695
178
$118 \dagger$

* Infusion less than 24 hours.

$\dagger$ Excretory rate.

of unlabeled carrier hormone and demonstration of constant specific activity after column or paper chromatography in at least two systems and $b$ ) demonstration of a single peak with a radioactive scanner. When samples were found to be impure, the entire batch was purified or rejected. At the beginning of each study 1 or $2 \mu \mathrm{c}$ of the labeled hormone dissolved in 5 to $10 \mathrm{ml}$ of $10 \%$ ethanol was given intravenously. The subsequent 24-hour urine collection was incubated at $\mathrm{pH} 1$ for 24 hours. Aldosterone liberated by this procedure was identified and eluted from a toluene-propylene-glycol paper chromatogram. The sample was then acetylated with $\mathrm{C}^{\mathbf{1}}$ - acetic anhydride to form aldosterone diacetate. After another paper chromatogram the doubly labeled aldosterone diacetate was finally purified by elution from a Celite column chromatogram. From the $\mathrm{H}^{3} / \mathrm{C}^{14}$ ratio of the purified sample the specific activity of the urinary aldosterone that had been released by acid hydrolysis was determined. From this, the 24-hour adrenal secretory rate was calculated, employing conventional isotope dilution equations. Twenty-four hour excretory rates of the acid-labile conjugate of aldosterone were also measured. A known amount of labeled hormone was added directly to the urine after acid hydrolysis but before extraction. 
TABLE III

Prolonged angiotensin infusion: increasing pressor sensitivity of normal subjects on a normal salt intake; reduced sensitivity after sodium depletion; tachyphybaxis in cirrhosis

\begin{tabular}{|c|c|c|c|c|c|c|c|c|}
\hline & \multirow{2}{*}{$\begin{array}{l}\text { No. } \\
\text { of } \\
\text { studies }\end{array}$} & \multirow{2}{*}{$\begin{array}{l}\text { Dura- } \\
\text { tion }\end{array}$} & \multicolumn{3}{|c|}{ Average blood pressure levels } & \multirow{2}{*}{$\begin{array}{l}\text { Cumulative sodium } \\
\text { balance during } \\
\text { infusions }\end{array}$} & \multicolumn{2}{|c|}{ Rate of administration } \\
\hline & & & Control & First day & Final day & & First day & Final day \\
\hline & & days & \multicolumn{3}{|c|}{$m m \mathrm{Hg}$} & $m E q$ & \multicolumn{2}{|c|}{$\begin{array}{c}\mu g / \min \\
\text { Angiotensin }\end{array}$} \\
\hline $\begin{array}{l}\text { Normal } \\
\text { (Normal diet) }\end{array}$ & 4 & $\begin{array}{l}6-11 \\
(9)^{*}\end{array}$ & $110 / 66$ & $140 / 90$ & $150 / 90$ & $\begin{array}{l}+3 \text { to }+178 \dagger \\
(+132)\end{array}$ & $\begin{array}{c}0.43-1.8 \\
(1.1)\end{array}$ & $\begin{array}{l}0.13-1.5 \\
(0.73)\end{array}$ \\
\hline $\begin{array}{l}\text { Normal } \\
\text { (Prolonged sodium } \\
\text { depleted) }\end{array}$ & 1 & 2 & $108 / 68$ & $145 / 100$ & $155 / 100$ & -73 & 2.2 & 3.6 \\
\hline Cirrhosis & 9 & $\begin{array}{l}2-6 \\
(3)\end{array}$ & $107 / 66$ & $145 / 85$ & $145 / 80$ & $\begin{array}{l}0 \text { to }-880 \\
(-216)\end{array}$ & $\begin{array}{c}2.4-7.1 \\
(4.9)\end{array}$ & $\begin{array}{c}3.3-20.7 \\
(8.4)\end{array}$ \\
\hline $\begin{array}{l}\text { Normal } \\
\text { (Normal diet) }\end{array}$ & 3 & $\begin{array}{l}3-4 \\
(4)\end{array}$ & $118 / 72$ & $155 / 85$ & $160 / 90$ & $\begin{array}{c}-68 \text { to }-162 \\
(-101)\end{array}$ & \multicolumn{2}{|c|}{$\begin{array}{cc}\text { Norepinephrine } \\
7.0-13.9 & 12.1-20.0 \\
(9.3) & (16.4)\end{array}$} \\
\hline $\begin{array}{l}\text { Normal } \\
\text { (Prolonged sodium } \\
\text { depleted) }\end{array}$ & 1 & 2 & $116 / 60$ & $160 / 85$ & $165 / 85$ & -53 & 25.6 & 30.1 \\
\hline Cirrhosis & 5 & $\begin{array}{l}2-4 \\
(3)\end{array}$ & $107 / 63$ & $165 / 80$ & $170 / 85$ & -2 to -94 & $\begin{array}{c}12.9-39.4 \\
(26.2)\end{array}$ & $\frac{12.2-46.4}{(29.4)}$ \\
\hline
\end{tabular}

* Numbers in parentheses $=$ average.

$\dagger$ The peak positive sodium balances were higher owing to escape (see text).

Recovery experiments utilizing these procedures indicate an experimental error of less than $\pm 5 \%$ for both methods. By this method normal subjects on unrestricted diets exhibit secretory rates of from 75 to $250 \mu \mathrm{g}$ per day and excretory rates of from 7 to $25 \mu \mathrm{g}$ per day. Full details of these modifications of an earlier method (2) will be reported elsewhere (23). Secretory rates of hydrocortisone were determined by the isotope dilution method of Romanoff and co-workers (24) employing tritium-labeled cortisol. The normal range for elderly people is 12 to $23 \mathrm{mg}$ per day by this method; for younger people, 16 to $31 \mathrm{mg}$ per day.

\section{Results}

Infusions of pressor agents were classified as either brief ( 8 to 24 hours duration) or prolonged. Results of all the 8- to 24-hour infusion studies are presented in Tables I and II. Prolonged infusions varied in duration but were never less than 2 days. Data from the prolonged infusions are summarized in Table III. Twelve balance studies of eight subjects who received prolonged infusions are presented in Figures 1 to 5 .

\section{Effects on arterial blood pressure}

Normal subjects; normal sodium. As in other reports, angiotensin was about ten times more potent (by weight) than norepinephrine in producing a given rise in arterial pressure. In general, it had a greater effect on the diastolic pressure than did norepinephrine (25). During prolonged infusions all four subjects became increasingly sensitive to the pressor effects of angiotensin as the drug concurrently produced sodium and water retention (Table III, Figures 1 and 2). Thus blood pressure was maintained with progressively diminishing doses of angiotensin. An increase in potassium intake did not modify the pressor response of one normal subject (no. 5).

In sharp contrast, norepinephrine produced little or no sodium retention, and increasing rather than decreasing doses of pressor agent were required to maintain the pressor response of three normal subjects (Table III, Figure 3 ).

Normal subjects; low sodium. The state of sodium depletion in these subjects was progressive, as indicated by serially lower rates of sodium excretion together with increased rates of aldosterone secretion in control periods. Eight infusions of angiotensin and four of norepinephrine revealed graded declines in pressor sensitivity as sodium depletion progressed.

After several weeks of sodium deprivation, $\mathrm{Pa}$ tient no. 7 developed a rather impressive reduction in pressor sensitivity. His initial dose requirement for angiotensin was increased from $1.9 \mu \mathrm{g}$ per minute to $2.6 \mu \mathrm{g}$ per minute, and for norepinephrine was elevated to $29.4 \mu \mathrm{g}$ per minute. After 2 months of continued rigid sodium deprivation in this man, no additional reduced pressor respon- 



Fig. 1. Prolonged angiotensin infusion in normal subjects. AlDOSTERONE SECRETION, PRESSOR SENSITIVITY, SODIUM RETENTION, AND "ESCAPE." Subject A. S. had been on a low sodium diet for several weeks before the study began. E. H. had been on a normal sodium intake for about the same period. In the salt-depleted subject, pressor sensitivity to angiotensin did not change during a 6-day infusion. It continued to stimulate increased aldosterone secretion, but there were no significant changes in electrolyte balance. In contrast, in the subject receiving a normal salt diet angiotensin produced a positive sodium balance. With this, a markedly increased pressor sensitivity developed so that at the end of an 11-day period relatively minute doses of angiotensin were required to maintain the mild pressor response. "Escape" from sodium retention began on day 5. As her angiotensin dosage was reduced, aldosterone secretion diminished falling almost back to the control levels. These data suggest a normal homeostatic interaction between the state of salt balance and the pressor and the aldosterone stimulating effects of angiotensin.

siveness to either agent appeared, but dosages of both agents required further increases on the second day of each 2-day infusion study (Table III).
Patients with cirrhosis and ascites. On the average these patients had a fourfold reduction in pressor sensitivity to angiotensin (Table II and III). This reduction was greater than the similar 



Fig. 2. Prolonged angiotensin Infusion in NORMal SUBJECTS ON A NORMAL SODIUM INTAKE. In R. P., a mildly pressor dose of angiotensin induced a marked and selective increase in adrenal cortical secretion of aldosterone together with a moderate degree of sodium retention for 4 days. Because of increasing pressor sensitivity to angiotensin, dosage was reduced, and aldosterone secretion returned toward control levels. "Escape" from more renal sodium retention occurred here as levels of the sodium-retaining substances, angiotensin and aldosterone, declined, but at this point blood pressure remained mildly elevated. In subject J. E. angiotensin produced persistent hypersecretion of aldosterone, and at this high dosage level it also stimulated cortisol secretion. As in the other normal subjects, sensitivity to angiotensin increased as sodium retention progressed. In this particular study it was not clear why sodium retention did not begin until day 3 .

depression seen in sodium-depleted normals. With more prolonged infusions these cirrhotic patients had tachyphylaxis to the pressor effects of angiotensin so that progressively increasing dosages were necessary to maintain the pressor response. Tachyphylaxis was consistently observed in the six cirrhotic patients receiving $2.4 \mu \mathrm{g}$ per minute or more. In dosages below this level it did not occur in two cirrhotic patients. Pressor sensitivity to norepinephrine was not reduced to a similar extent nor was tachyphylaxis observed.

\section{Effects on the rates of aldosterone secretion and excretion}

Normal subjects; normal sodium. Infusion of angiotensin uniformly increased aldosterone secretion by 202 to $511 \%$ of the control rates with a mean of $+360 \%$. Prolonged infusion of angiotensin in four subjects (Patients no. 2 to 5 ) for from 2 to 11 days always produced a sustained rise in aldosterone secretion. In three of these angiotensin dosage was progressively reduced as pressor sensitivity increased. Even with these
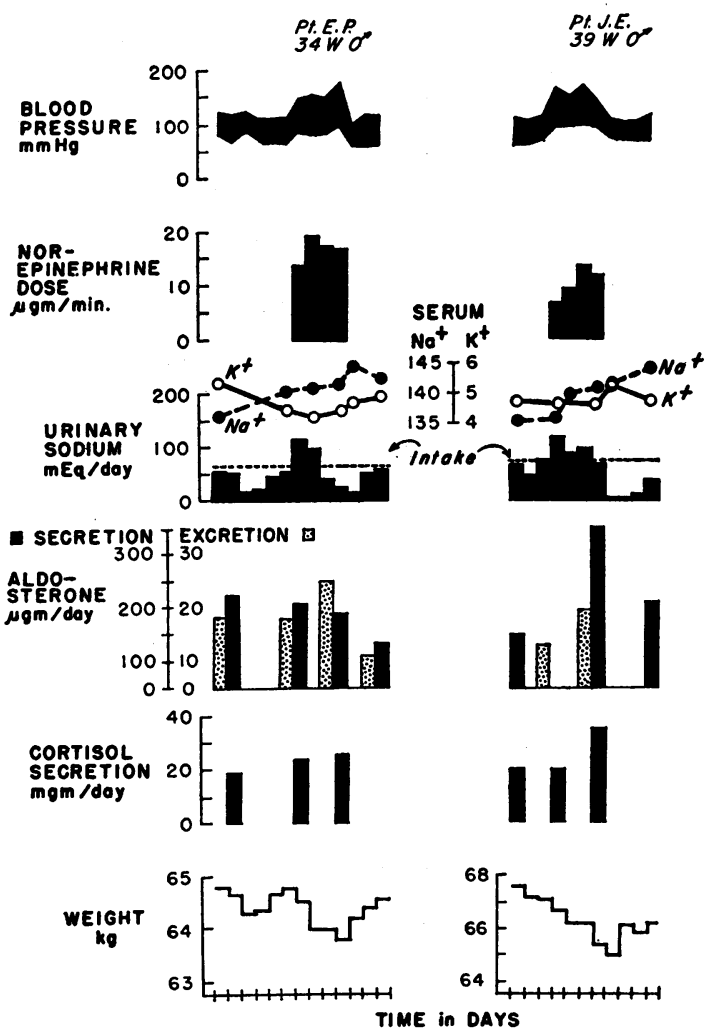

Fig. 3. RESPONSE TO NOREPINEPHRINE IN NORMAL SUBJECTS. In normal subjects on a diet containing $\mathbf{7 0}$ $\mathrm{mEq}$ of sodium, prolonged infusion of norepinephrine in pressor dosage was not associated with tachyphylaxis in subject E. P., but in subject J. E. graded increases in doses were required. In both studies, a mild natriuresis was produced followed by a period of salt retention. The transient natriuresis was accompanied by a relatively greater increase in urinary volume. In both studies these effects may have accounted for the mild hypernatremia and weight loss. There were no significant effects on aldosterone or cortisol secretion in subject E. P. In subject J. E. norepinephrine produced a rise in both cortisol and aldosterone secretion, possibly suggesting that a release of ACTH had occurred. 


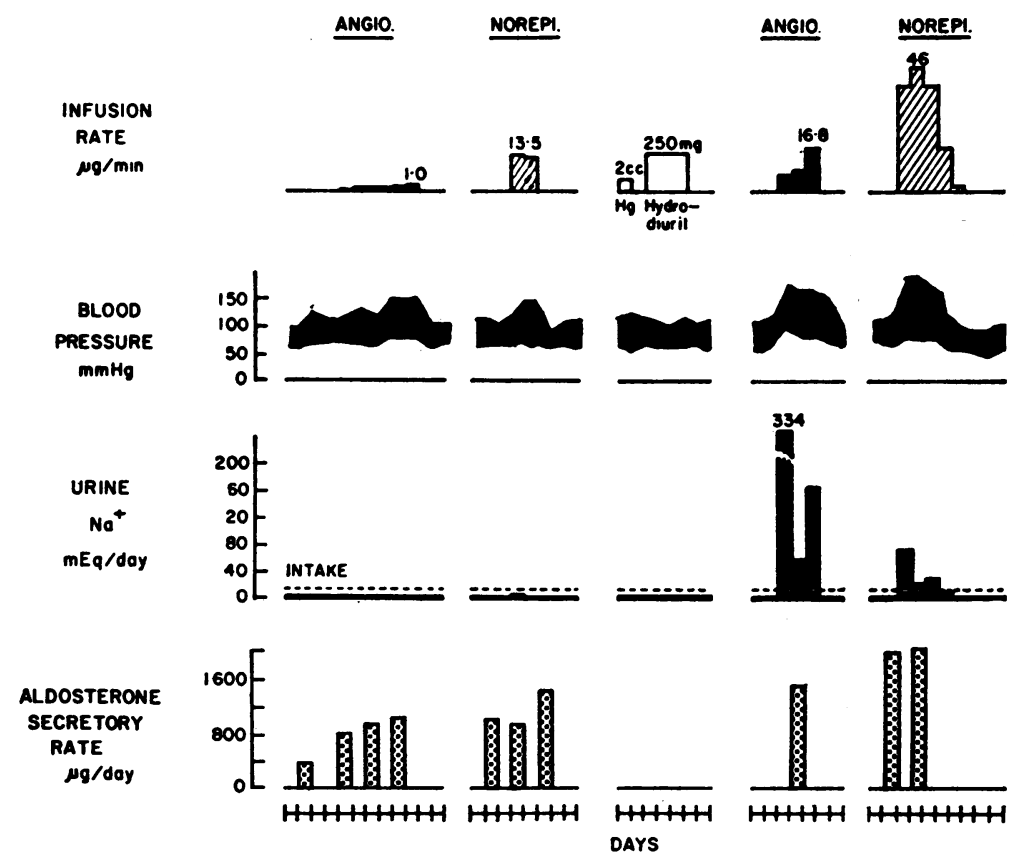

Fig. 4. PROLONGED ANGIOTENSIN AND NOREPINEPHRINE INFUSIONS IN A PATIENT WITH CIRRHOSIS AND ASCITES. Infusions of angiotensin and norepinephrine at comparatively smaller doses failed to affect the arterial pressure, the electrolyte balance, or the already high aldosterone secretion. The patient exhibited complete unresponsiveness to a mercurial diuretic and hydrochlorothiazide. Infusion of angiotensin at a larger dosage produced mild increases in blood pressure, a remarkable natriuresis, and clearing of edema fluid. Larger doses of norepinephrine that produced similar increases in blood pressure produced a smaller and more transient natriuresis. The natriuresis and diuresis produced by angiotensin were not the result of suppression of the high aldosterone secretion.

diminishing dosages aldosterone secretion rates tended to remain above the control values (Figures 1 and 2). Aldosterone secretion or excretion rates usually returned to control levels when measured 2 to 3 days after cessation of an infusion.

In contrast, norepinephrine infusions produced no consistent changes in aldosterone secretion during either three brief or three more prolonged infusion studies (Table I, Figure 3).

Normal subjects; low sodium. A significant stimulating effect of angiotensin on aldosterone secretion was apparent after prior sodium depletion in seven of the eight brief infusion studies (Table I). The already elevated control values were augmented by from 43 to $116 \%$ (mean $+97 \%$ ). Both before and after sodium depletion fairly similar dosages of angiotensin were given, and similar absolute rates of aldosterone secretion were attained. Therefore, after sodium depletion the increment in aldosterone secretion appeared to be blunted in proportion to the degree of underlying increase in endogenous aldosterone secretion. Mean angiotensin-induced increments in aldosterone secretion rates were $+650 \mu \mathrm{g}$ per day before sodium depletion and only $+350 \mu \mathrm{g}$ per day after depletion (Table I). After several weeks of sodium deprivation, aldosterone was persistently augmented in Subject no. 7 during a 6-day infusion study (A.S., Figure 1).

Patients with cirrhosis and ascites. It is clear that angiotensin did not increase aldosterone secretion in cirrhosis to anywhere near the extent observed in normal subjects. Secretion was generally already elevated to some extent, and in general, the lower the initial rate of aldosterone secretion the higher the increment in secretion. However, these increases resulted from doses of 


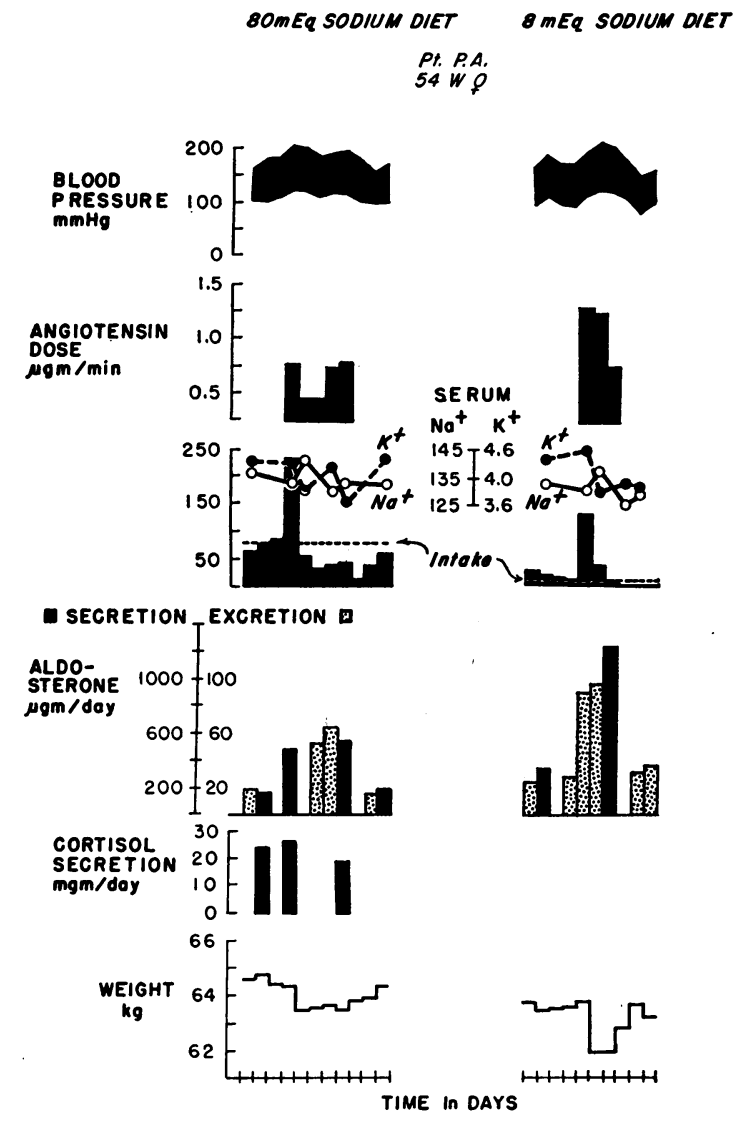

Fig. 5. Prolonged angiotensin infusion in UNCOMPLICATED ESSENTIAL HYPERTENSION. Unlike normal subjects angiotensin infusion produced natriuresis and diuresis on the first day of the infusion whether or not sodium depletion had been imposed. In both studies aldosterone continued to be increased above normal control levels for as long as the infusion was applied. Angiotensin stimulated aldosterone secretion without also causing an increase in cortisol secretion. In a later study, with norepinephrine, aldosterone secretion was not affected. Pressor sensitivity to angiotensin was reduced after sodium depletion. Unlike normal subjects prolonged infusion of angiotensin was associated with neither sodium retention nor increasing pressor sensitivity.

angiotensin far in excess of those given to normal subjects. At the dose level commonly employed for normal subjects we saw little or no effect.

Several diverse effects should be noted. Two patients (no. 12 and no. 16) showed increases in aldosterone in control periods while being maintained on low sodium diets and subsequent to diuresis induced by angiotensin. Two patients (no. 11 and no. 18), who did not show secondary aldosteronism in connection with cirrhosis, also did not show any increases in aldosterone secretion with angiotensin. This is the first time we have ever observed the failure of angiotensin to increase low secretory rates of aldosterone. When dexamethasone was given to two patients to suppress ACTH release, angiotensin augmented aldosterone secretion without modifying their negligible rates of cortisol secretion.

Equipressor amounts of norepinephrine reduced aldosterone secretion in six infusions and had no significant effect in three infusions (Table II, Figure 6).

\section{Effects on cortisol secretion (Tables I and II, Fig- ures 1 to 3, 5, and 7)}

Angiotensin did not produce any uniform or striking effects on cortisol secretion in normal subjects. Figure 2 shows that one subject showed a $100 \%$ increase after prolonged infusion. However, two other subjects experienced no effect (Figures 1 and 2).

Norepinephrine did not stimulate cortisol secretion in four infusion studies of normal subjects on normal sodium intake (Table I and Figure 3 ).

In cirrhosis, the comparatively large doses of angiotensin that were administered produced impressive increases in cortisol secretion without any great increases in aldosterone secretion ( $\mathrm{Ta}$ ble II). A similar pattern obtained in one cirrhotic patient given norepinephrine.

\section{Effects on plasma electrolytes and sodium and po- tassium balance}

Normal subjects; normal sodium. Except for Subject no. 5, brief infusions of angiotensin always produced renal retention of sodium. Prolonged infusions from 6 to 11 days also produced moderate sodium and water retention in all four subjects. The positive sodium balance during prolonged infusions ranged from 90 to $265 \mathrm{mEq}$ (average maximum: $200 \mathrm{mEq}$ ). This retention was accompanied by a weight gain of 1 to $2.5 \mathrm{~kg}$, but edema was never clinically detectable. These patients showed the so-called "escape" from renal retention, when, after 3 to 5 days of sodium retention, there was a tendency to excrete more sodium. At the termination of the infusions the positive sodium balances ranged from 3 to 178 $\mathrm{mEq}$ with a mean of $+132 \mathrm{mEq}$. 
ANGIOTENSIN
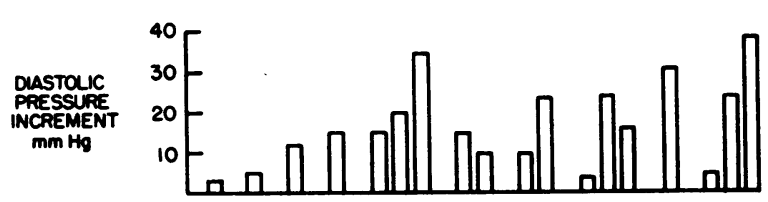

$\underset{\text { UNAV }}{\Delta \text { INQdoy }}$
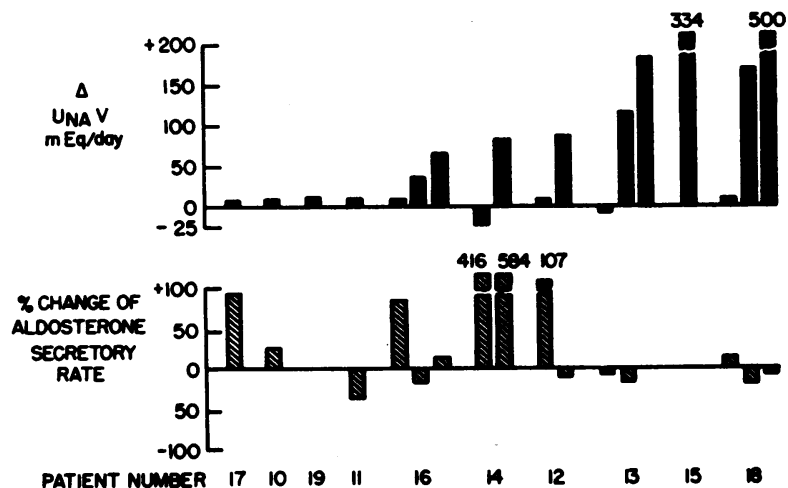

NOREPINEPHRINE


Fig. 6. Natriuresis in Patients with CirRhosis and ascites. Patient numbers correspond to those of Table II. The patients are arranged according to increasing urinary sodium excretion during an 8- to 24-hour angiotensin infusion. Natriuresis with angiotensin is correlated with increases in diastolic arterial pressure. Similar pressure increments due to norepinephrine did not produce a significant natriuresis. When angiotensin infusions were accompanied by a marked further increase in aldosterone secretion, natriuresis generally did not appear. Patients 12 to 14,16 , and 18 had repeated angiotensin infusions. Each was separated by an interval of several days.

These four subjects showed a tendency to hyponatremia. Plasma sodium levels declined by an average of $5 \mathrm{mEq}$ per $\mathrm{L}$. They also developed a negative potassium balance. Cumulative loss ranged from 14 to $70 \mathrm{mEq}$ with an average loss of $36 \mathrm{mEq}$. A slight tendency to hypokalemia was observed with an average fall of $0.5 \mathrm{mEq}$ per L. Plasma bicarbonate levels remained below $30 \mathrm{mEq}$ per $\mathrm{L}$ throughout. Three of these studies are presented in Figures 1 and 2.

Brief infusions of norepinephrine, unlike angiotensin, produced variable effects on electrolyte excretion. With prolonged infusions of 2 to 4 days three subjects showed a slight natriuresis and a more marked diuresis in the first 1 to 3 days. This was followed by mild sodium retention and a return to sodium balance but at a slightly lower weight. In these three studies the plasma sodium levels rose from 4.5 to $6.6 \mathrm{mEq}$ per $\mathrm{L}$ with a mean of $5.5 \mathrm{mEq}$ per L. Perhaps this is because norepinephrine produced a relatively greater increase in water excretion. Upon cessation of infusion renal retention of salt and water was observed until weight returned to control values. Potas- sium balance did not change appreciably during norepinephrine infusion. It remained slightly positive, averaging $+18 \mathrm{mEq}$ per $\mathrm{L}$. Two of these norepinephrine studies are presented in Figure 3.

Normal subjects; low sodium. In seven of eight brief infusions angiotensin did not usually modify the low rate of sodium excretion. One patient (no. 7) did show a slight sodium diuresis. However, this subject (A.S., Figure 1) exhibited no change in fluid and electrolyte balance during 6 days of mildly pressor infusion. After 2 months of salt deprivation, he received a higher somewhat more pressor dosage (2.2 $\mu \mathrm{g}$ per minute). This time a mild natriuresis occurred on the first day followed by a decrease in pressor response, (Table I, no. 7, and Table III). Brief infusions of norepinephrine in four sodium-depleted subjects caused no change in three and a mild natriuresis in one (Table I). In one subject a 2-day infusion of norepinephrine continued to produce mild natriuresis with slightly declining pressor sensitivity (Table III).

Patients with cirrhosis and ascites. In ten pa- 
tients 22 brief infusions of angiotensin resulted in ten instances of natriuresis in which there was an average increase in sodium excretion of $183 \mathrm{mEq}$ per day (range, 37 to $501 \mathrm{mEq}$ per day). In general, occurrence and degree of natriuresis seemed related to both the degree of pressor response and the amount of angiotensin administered. Nine prolonged infusions were conducted in six patients. Four of the nine had natriuresis. This natriuresis tended to diminish, even when dosages were increased to maintain the pressor response. However, in one patient (no. 18) natriuresis resulted in complete diuresis of edema fluid and a 6-kg weight loss in 3 days. Two other patients showed a considerable reduction in ascites (Figure 4). Natriuresis in two subjects was accompanied by significant hyponatremia. Negative potassium balance accompanied natriuresis (increments of 20 to $80 \mathrm{mEq}$ per day) during seven studies of four patients.

Nine brief infusions of equipressor amounts of norepinephrine caused much smaller increases in sodium excretion. Only three patients showed significant natriuresis, the average increases being $33 \mathrm{mEq}$ per day (range, 7 to $54 \mathrm{mEq}$ per day) (Table II). Prolonged infusions lasting up to 4 days produced a mild diminishing natriuresis with a maximal loss of $94 \mathrm{mEq}$ in 4 days in two of the five studies. Plasma electrolytes were not changed. The differences between norepinephrine and angiotensin in cirrhosis are illustrated in Figure 6.

Untoward effects. During the sixth day of a continuous angiotensin infusion a 36-year-old normal volunteer (no. 4) suffered a cerebral hemorrhage and expired within 24 hours. The episode occurred while straining at stool. Autopsy confirmed the diagnosis, but the ruptured cerebral vessel could not be located. There was no evidence of gross or microscopic damage to the cerebral vessels or pre-existing vascular injury. The heart, kidneys, and adrenals were entirely normal histologically. Blood pressure was $180 / 100$ a few minutes before this accident occurred.

This man, receiving $80 \mathrm{mEq}$ of sodium daily, had demonstrated sodium retention $(265 \mathrm{mEq}$ in 5 days) and then began to "escape" with urinary sodium excretion rising from a low of $2 \mathrm{mEq}$ per day on day 2 to $127 \mathrm{mEq}$ per day on day 6. Possibly this sodium retention predisposed to a subtle but serial rise in pressor sensitivity, leading to an inordinate rise in blood pressure during straining. Pressure rises from angiotensin or norepinephrine have not heretofore been related to cerebral bleeding in extensive studies of animals and man. Throughout this study the infusion rate was 1.5 $\mu \mathrm{g}$ per minute, a rate well below that employed in other reports (26-34). Because of this occurrence, this study and all other investigations with infusions of pressor agents were terminated immediately.

In general, blood pressure responses occurred within 1 to 2 minutes after the infusion of either agent. Usually, patients were unaware of the change in blood pressure; some noted occasional palpitation, but none had chest pain. Transient headache was occasionally observed with pressor doses of both drugs. No serious cardiac arrhythmias were encountered, although there were very occasional extrasystoles. When infusion of either agent ceased, there was almost always a period of hypotension that was more pronounced after prolonged infusions. The fall in blood pressure was principally orthostatic and lasted about 1 to 6 hours. A "weaning" period was often necessary after some of the more prolonged infusions in cirrhosis, lasting about several hours, but occasionally as long as several days.

\section{Discussion}

Our experiments with prolonged infusions of angiotensin appear to establish several facts. The prolonged aldosterone hypersecretion secondary to the infusion of angiotensin produces slightly different physiological changes than those previously described for the continued administration of aldosterone (35). Infusion of angiotensin produces more immediate and impressive increases in arterial blood pressure; it produces hyponatremia instead of hypernatremia and shows less tendency for potassium wastage and alkalosis. Therefore, while the administration of aldosterone duplicates the abnormalities found in primary aldosteronism, the effects of angiotensin infusion appear to resemble those of aldosteronism associated with malignant nephrosclerosis (2). Thus, angiotensin and aldosterone cannot be equated as physiological agents, but we have obtained considerable evidence indicating that angiotensin could operate as a trophic hormone for the stimulation of aldos- 
terone secretion, in the mechanism outlined in the introduction.

In normal subjects angiotensin stimulated aldosterone secretion selectively and persistently, in lower, mildly pressor doses. Small doses of angiotensin stimulate aldosterone secretion exclusively; at larger dose levels where aldosterone secretion cannot be further increased, cortisol stimulation occurs (Figure 7). This pattern of adrenal cortical responsiveness is the opposite of that seen with ACTH, where cortisol secretion is selectively stimulated at lower doses and aldosterone stimulation occurs at higher levels after cortisol secretion approaches a maximum. Although angiotensin has a direct stimulating effect on the adrenal cortex (14-16), a subtle discharge of ACTH may have been responsible for the occasionally observed rise in cortisol secretion. Evidence for this was obtained in the two cirrhotic patients in whom dexamethasone suppression blocked the usual cortisol stimulating effect of higher angiotensin dosage.

As in previous reports $(3,4,28)$, the dosages of angiotensin required to stimulate aldosterone secretion nearly always were sufficient to produce small but definite increases in arterial blood pressure. In one report in which nonpressor amounts of angiotensin were said to stimulate aldosterone, significant elevations of pressure were described (4). We observed stimulation of aldosterone secretion with nonpressor dosages of angiotensin only once in these experiments. Otherwise the bulk of our data indicates that dosages exceeding $0.2 \mu \mathrm{g}$ per minute of angiotensin were required to produce significant stimulation of aldosterone secretion. At this level pressor effects were small but evident.

The stimulation of aldosterone secretion by angiotensin therefore appears to be closely associated with its pressor action. However, pressor agents, in general, do not stimulate aldosterone secretion. Norepinephrine and other pressor agents (3) produce only slight and variable effects on aldosterone secretion. Moreover, the data presented in this paper indicate that both the pressor activity and the aldosterone stimulating activity of exogenous angiotensin are related to sodium balance. We could not demonstrate this or any similar relationship with norepinephrine.

In this study stimulation of aldosterone secre- tion by angiotensin continued for as long as the drug was applied and returned to control levels when application ceased. In contrast, in sheep the stimulating effect of angiotensin on aldosterone secretion did not persist after 6 hours (16). However, a sustained stimulation for many days in dogs receiving nonpressor infusions has been reported (19). The ineffectiveness of nonpressor dosages in stimulating aldosterone secretion in man may perhaps be explained by a species difference. Man appears quantitatively more sensitive than animals to the pressor effects of angiotensin $(19,36)$.

There appeared to be a limit to the increases that angiotensin can effect on aldosterone secretion. Aldosterone secretion rates were increased to approximately the same absolute levels both before and after sodium deprivation. The peptide therefore had relatively less augmenting effect in sodium-depleted subjects in whom aldosterone secretion was already elevated. Angiotensin failed completely to increase the often high aldosterone secretion of patients with cirrhosis and ascites, even though the much larger doses given to these patients increased cortisol secretion. The partial aldosterone response of sodium-depleted normal subjects and the total lack of response in cirrhosis and ascites point to a ceiling for adrenal response to angiotensin. Increased endogenous angiotensin might be the basis for the elevated aldosterone secretion that occurs naturally in both of these situations. Pre-existing angiotensinemia could explain the blunted aldosterone response of the sodium-depleted normal subjects. A still higher endogenous level of angiotensin in cirrhosis would account for the total failure of infused angiotensin to stimulate aldosterone secretion.

Differences between the pressor sensitivity to angiotensin and norepinephrine were observed that seemed to be related to the different effects of the two agents on sodium balance. In normal subjects, angiotensin produced sustained sodium chloride retention. This was regularly accompanied by a graded increase in pressor sensitivity. In contrast, norepinephrine caused either natriuresis or no significant change in sodium balance, and pressor sensitivity tended to diminish as the infusion proceeded. In acute experiments norepinephrine too causes renal sodium retention (25), but the present study indicates that an 
early escape from this effect occurs. Increasing vascular sensitivity to prolonged angiotensin infusion was also recently described in rabbits (37). This phenomenon was not related to sodium balance.

In general, sodium depletion diminishes pressor responsiveness and enhances the effectiveness of antipressor drugs. Thus, pressor sensitivity to both angiotensin and norepinephrine was reduced somewhat after sodium depletion of normal subjects and to a greater extent in cirrhosis with ascites (Table III). These patients were particularly insensitive to angiotensin and tended to become increasingly unresponsive (i.e., to develop tachyphylaxis). This phenomenon seemed quantitatively related to the considerably greater natriuresis induced by the peptide as compared with norepinephrine. That sodium balance may be an important determinant of pressor sensitivity is further suggested by similar prolonged infusion studies of a hypertensive subject (Figure 5).

The state of sodium metabolism, therefore, seems important in determining pressor responsiveness, but the amount of angiotensin administered may also be involved. Tachyphylaxis was observed only in the six cirrhotic patients given dosages of $2.4 \mu \mathrm{g}$ per minute or more. However, a dose of $2.8 \mu \mathrm{g}$ per minute did not induce tachyphylaxis in a normal subject (J. E., Figure 2). This possible relationship to dosage may be similar to that reported in dogs (38) and in rabbits (36).

Patients with cirrhosis and ascites have large increases in body sodium content. Yet, in pressor responsiveness they behaved as though severely sodium depleted. This finding, together with the fact that the angiotensin-induced sodium accumulation of normal subjects actually increased pressor sensitivity to angiotensin, suggests that the abnormal distribution of retained sodium in edematous patients precludes it from supporting the action of pressor agents. Both the tendency to transudation in cirrhosis and the lack of edema in association with angiotensin-induced sodium accumulation of normal subjects suggest that the sodium retention of normal subjects increases pressor sensitivity by contributing to the volume or composition of the intravascular bed. The declining pressor sensitivity of edematous subjects during angiotensin natriuresis may have re- sulted from a further depletion of this intravascular sodium store.

In normal subjects as angiotensin caused sodium retention, pressor sensitivity increased to a point where the pressure elevation could be maintained by smaller dosages, which might not be expected to stimulate increased aldosterone secretion. This phenomenon might be relevant to the problem of hypertension associated with unilateral renal disease. In this condition one group has consistently found increased angiotensin release from the damaged kidney. Usually there was no attendant evidence of hyperaldosteronism (39). The amounts of angiotensin released by these patients might conceivably suffice to maintain hypertension (after sodium retention had been induced) without being sufficient to also maintain aldosteronism. This explanation might be in accord with Tobian's hypothesis of an increased sodium content of the arterial wall in experimental hypertension (40).

If the renin-angiotensin-aldosterone system is oriented to prevent salt depletion or arterial hypotension, the paradoxical natriuresis observed after larger, more pressor dosages of angiotensin in cirrhosis requires an explanation. This latter effect might result from an undue increase in arterial blood pressure in patients with a high endogenous angiotensin. ${ }^{1}$ In cirrhosis with nearly complete sodium retention the renal tubules and the adrenal cortex may be already responding maximally to an endogenous angiotensin stimulus. Administration of exogenous angiotensin in this situation exerts no further direct effect on the renal tubules or the adrenal cortex. The natriuresis therefore may be caused by the systemic pressor effects of excesses of the drug. This mechanism implies that increases of circulating levels of angiotensin and elevations of systemic blood pressure have opposing effects on renal sodium excretion. The sodium-retaining effect of lower doses

\footnotetext{
1 The indirect evidence for increased circulating angiotensin in cirrhosis is derived from the specifically decreased pressor sensitivity to this agent, the failure to further stimulate aldosterone secretion, and the presence of avid renal sodium retention all described herein and reported elsewhere $(41,42)$. McManus (43) described juxtaglomerular cell hyperplasia in human cirrhosis. Dogs with experimental ascites also have decreased angiotensin pressor sensitivity and increased renal and circulating renin activity and juxtaglomerular cell hyperplasia $(44,45)$.
} 


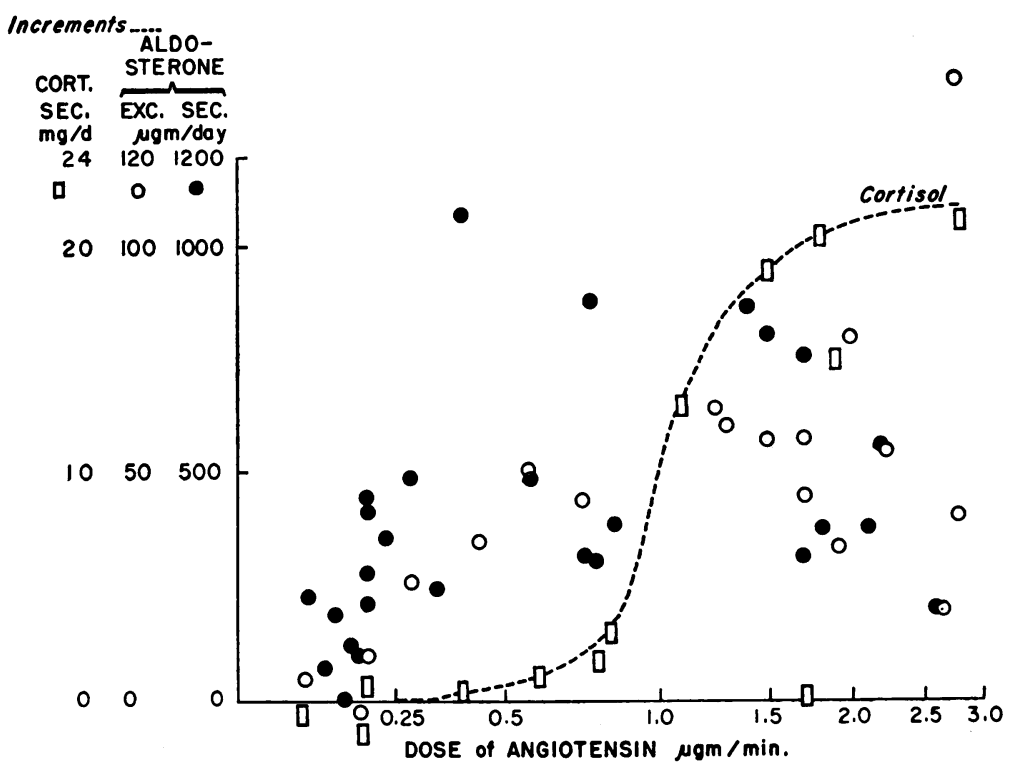

Fig. 7. RELationship of ANGIOTENSin dOSE to aldosterone and cortiSOL SECRETION. Data are taken from all studies of the normal subjects. Angiotensin appears to stimulate aldosterone secretion maximally at doses less than $0.5 \mu \mathrm{g}$ per minute. However, even the lower of these dosages cannot be defined as nonpressor. Although results with cortisol secretion are not conclusive, it appears that cortisol secretion is not significantly increased until large doses of angiotensin exceeding $0.5 \mu \mathrm{g}$ per minute are applied.

of angiotensin has been repeatedly demonstrated (25-27). Also, elevations of arterial pressure per se can promote natriuresis in normal animals, $(46-48)$ and more specifically in patients with cirrhosis and ascites $(25,49)$. Furthermore, patients with arterial hypertension (Figure 5) are much more prone than normal subjects to natriuresis when various pressor agents are infused $(28,30)$. Saline-loaded normal subjects can develop this natriuretic response to pressor infusions (50).

Operation of this interaction may provide an explanation for the mysterious "escape" from renal sodium retention induced by angiotensin in our normal subjects and also described in the dog (19). Sodium chloride retention of the order of +90 to $+265 \mathrm{mEq}$ was produced during the first 3 to 5 days of angiotensin infusions in subjects receiving a normal sodium intake. Escape from this renal sodium retention may be a "pressure" natriuresis resulting from the attainment of a critical increment in arterial pressure that overcomes the angiotensin-aldosterone initiated sodium retention.
Borst and Borst-de-Geus (51) have proposed that the "escape" phenomenon observed in normal subjects during mineralocorticoid administration is induced by a critical rise in arterial blood pressure resulting from sodium retention. Although their hypothesis may also prove correct, no consistent rise in arterial pressure was observed during this type of "escape" in a study of 17 normal subjects (52). Furthermore, this experimental situation differs from our study because one would expect endogenous renin and angiotensin to be suppressed by excess mineralocorticoid (9).

Despite a vast literature there is virtually no information about the effects of angiotensin on the cerebral circulation. No deleterious effects have been heretofore described. In view of the vascular accident observed in this study, additional studies are in order. Dickinson and Lawrence (37) have recently suggested that angiotensin is a specific cerebral vasoconstrictor. If this is so, it could play a role, not only in the pathogenesis of arterial hypertension, but also in the production of the associated encephalopathic syndromes and cerebral accidents. Because of the vascular acci- 
dent described herein infusion of all pressor agents in man should be approached with this possibility in mind until mechanisms can be worked out by further animal investigation.

Our data indicate that angiotensin is oriented to prevent sodium depletion or arterial hypotension. Loss of body sodium is associated with a tendency for a fall in arterial pressure; either may elicit the secretion of renin and the elaboration of angiotensin. Angiotensin then promotes salt retention both directly and by augmenting aldosterone secretion; as sodium stores increase, pressor sensitivity to angiotensin rises, leading to blood pressure elevation. Increased renin and aldosterone activity are then suppressed. If blood pressure rises excessively "pressure natriuresis" occurs, returning the sodium stores and blood pressure toward normal.

\section{Summary}

To obtain more information about a possible angiotensin-aldosterone interaction for regulation of sodium balance and arterial blood pressure, the effects of prolonged infusions of angiotensin and norepinephrine on blood pressure, electrolyte balance, and adrenal secretion rates of aldosterone and cortisol were studied in normal subjects and in a representative form of secondary hyperaldosteronism.

In normal subjects, norepinephrine in pressor dosage for 2 to 4 days usually produced transient natriuresis and diuresis associated with diminishing pressor responsiveness. In patients with cirrhosis, norepinephrine at times also produced significant, although transient, natriuresis and diuresis. Pressor responsiveness was reduced, but tachyphylaxis was not impressive.

Angiotensin produced quite different effects. In normal subjects an initial marked renal retention of sodium chloride occurred, paralleled by increasing pressor sensitivity. After the initial 3to 5-day period "escape" occurred with increased renal salt excretion and a tendency for the weight to stabilize. Angiotensin also produced prompt and sustained increases in aldosterone but not in cortisol secretion. In sodium-depleted normal subjects sodium accumulation was prevented, and pressor responsiveness remained reduced.

In cirrhosis with ascites angiotensin often produced a striking natriuresis with diuresis of edema.
These patients exhibited pressor unresponsiveness and tachyphylaxis to angiotensin.

The stimulating capacity of exogenous angiotensin on aldosterone secretion was a graded one, related directly to the state of sodium balance and inversely to the pre-existing rate of aldosterone secretion. In normal subjects angiotensin augmented aldosterone secretion by a mean of $360 \%$ before and by only $97 \%$ after sodium depletion. In cirrhosis, larger doses of angiotensin failed completely to increase the already high aldosterone secretion. But these larger dosages were capable of increasing cortisol secretion.

Our findings indicate that the state of sodium balance is an important determinant of vascular responsiveness to both pressor agents. However, a direct, internally controlled relationship between the vasoactivity of angiotensin and the state of sodium balance was suggested because in normal subjects pressor sensitivity increased with an angiotensin-induced sodium retention, and it decreased after sodium depletion. Also the pressor unresponsiveness of cirrhosis became enhanced, and tachyphylaxis often developed after angiotensin natriuresis.

The data imply that under a certain circumstance, angiotensin-induced sodium retention, pressor sensitivity may increase so that hypertension can be sustained by amounts of angiotensin insufficient to also stimulate aldosterone. This point may be relevant to the pathogenesis of certain hypertensive states.

Angiotensin meets certain major criteria for an aldosterone-stimulating hormone because its action on the adrenal cortex appeared selective and persistent, and it could be demonstrated in mildly pressor dosage. Because of this and because the vasoactivity of angiotensin interacted with the state of sodium metabolism, a mechanism has been proposed in which angiotensin release participates, with aldosterone, in normal regulation of sodium balance and arterial blood pressure. The angiotensin-induced "escape" observed in the normal subjects and the paradoxical natriuresis observed in patients with cirrhosis might be explained in terms of this proposed mechanism.

\section{References}

1. Laragh, J. H. The role of aldosterone in man. Evidence for regulation of electrolyte balance and arterial pressure by a renal-adrenal system 
which may be involved in malignant hypertension. J. Amer. med. Ass. 1960, 174, 293.

2. Laragh, J. H., S. Ulick, V. Januszewicz, Q. B. Deming, W. G. Kelly, and S. Lieberman. Aldosterone secretion and primary and malignant hypertension. J. clin. Invest. 1960, 39, 1091.

3. Laragh, J. H., M. Angers, W. G. Kelly, and S. Lieberman. Hypotensive agents and pressor substances. The effect of epinephrine, norepinephrine, angiotensin II and others on the secretory rate of aldosterone in man. J. Amer. med. Ass. 1960, 174, 234.

4. Genest, J., P. Biron, E. Koiw, W. Nowaczynski, M. Chrétien, and $\mathrm{R}$. Boucher. Adrenocortical hormones in human hypertension and their relation to angiotensin. Circulat. Res. 1961, 9, 775.

5. Deane, H. W., and G. M. C. Masson. Adrenal cortical changes in rats with various types of experimental hypertension. J. clin. Endocr. 1951, 11, 193.

6. Dunihue, F. W. The effect of bilateral adrenalectomy on the juxtaglomerular apparatus (abstract). Anat. Rec. 1946, 96, 536.

7. Hartroft, P. M., and W. S. Hartroft. Studies on renal juxtaglomerular cells. I. Variations produced by sodium chloride and desoxycorticosterone acetate. J. exp. Med. 1953, 97, 415.

8. Dunihue, F. W., and W. Van B. Robertson. The effect of desoxycorticosterone acetate and of sodium on the juxtaglomerular apparatus. Endocrinology 1957, 61, 293.

9. Gross, F., and F. Sulser. Der Einfluss der Nebinieren auf die blutdrucksteigernde Wirkung von Renin und auf pressorische Substanzen en den Nieren. Arch. exp. Path. 1957, 230, 274.

10. Pitcock, J. A., and P. M. Hartroft. Pressor activity (renin) of kidneys from sodium-deficient rats and correlation with granulation of juxtaglomerular cells. Fed. Proc. 1959, 18, 500.

11. Deane, H. W., J. H. Shaw, and R. O. Greep. The effect of altered sodium or potassium intake on the width and cytochemistry of the zona glomerulosa of the rat's adrenal cortex. Endocrinology 1948, 43, 133.

12. Hartroft, P. M., and W. S. Hartroft. Studies of renal juxtaglomerular cells. II. Correlation of the degree of granulation of the juxtaglomerular cells with the width of the zona glomerulosa of the adrenal cortex. J. exp. Med. 1955, 102, 205.

13. Gross, F., P. Loustalot, and F. Sulser. Die Bedeutung von Kochsalz für den Cortexonhochdruch der Ratte und den Gehalt der Nieren an Pressorischen Substanzen. Arch. exp. Path. 1956, 229, 381.

14. Davis, J. O., C. C. J. Carpenter, C. R. Ayers, J. E. Holman, and R. C. Bahn. Evidence for secretion of an aldosterone-stimulating hormone by the kidney. J. clin. Invest. 1961, 40, 684.

15. Ganong, W. F., P. J. Mulrow, A. Boryczka, and G. Cera. Evidence for a direct effect of angio-
tensin-II on adrenal cortex of the dog. Proc. Soc. exp. Biol. (N. Y.) 1962, 109, 381.

16. Blair-West, J. R., J. P. Coghlan, D. A. Denton, J. R. Goding, J. A. Munro, R. E. Peterson, and M. Wintour. Humoral stimulation of adrenal cortical secretion. J. clin. Invest. 1962, 41, 1606.

17. Davis, J. O., C. R. Ayers, and C. C. J. Carpenter. Renal origin of an aldosterone-stimulating hormone in dogs with thoracic caval constriction and in sodium-depleted dogs. J. clin. Invest. 1961, 40, 1466.

18. Laragh, J. H. Hormones and the pathogenesis of congestive heart failure: vasopressin, aldosterone and angiotensin II. Further evidence for renaladrenal interaction from studies in hypertension and in cirrhosis. Circulation 1962, 25, 1015.

19. Urquhart, J., J. O. Davis, and J. T. Higgins, Jr. Effects of prolonged infusion of angiotensin II in normal dogs. Amer. J. Physiol. 1963, 205, 1241.

20. Bartter, F. C., A. G. T. Casper, C. S. Delea, and J. D. H. Slater. On the role of the kidney in control of adrenal steroid production. Metabolism 1961, 10, 1006.

21. Carpenter, C. C. J., J. O. Davis, and C. R. Ayers. Relation of renin, angiotensin II, and experimental renal hypertension to aldosterone secretion. J. clin. Invest. 1961, 40, 2026.

22. Mulrow, P. J., and W. F. Ganong. Stimulation of aldosterone secretion by angiotensin II. Yale J. Biol. Med. 1961, 33, 386.

23. Sealey, J., and J. H. Laragh. To be published.

24. Romanoff, L. P., C. W. Morris, P. Welch, R. M. Rodriguez, and G. Pincus. The metabolism of cortisol-4-C $\mathrm{C}^{14}$ in young and elderly men. I. Secretion rate of cortisol and daily excretion of tetrahydrocortisol, allotetrahydrocortisol, tetrahydrocortisone and cortolone $(20 \alpha$ and $20 \beta)$. J. clin. Endocr. 1961, 21, 1413.

25. Laragh, J. H., P. J. Cannon, C. J. Bentzel, A. M. Sicinski, and J. I. Meltzer. Angiotensin II, norepinephrine, and renal transport of electrolytes and water in normal man and in cirrhosis with ascites. J. clin. Invest. 1963, 42, 1179.

26. Bock, K. D., and H.-J. Krecke. Die Wirkung von synthetischem Hypertensin II auf die PAH- und Inulin-Clearance, die renale Hämodynamik und die Diurese beim Menschen. Klin. Wschr. 1958, 36, 69.

27. Bock, K. D., H. Dengler, H.-J. Krecke, and G. Reichel. Untersuchungen über die Wirkung von synthetischem Hypertensin II auf Elektrolythaushalt, Nierenfunktion und Kreislauf Beim Menschen. Klin. Wschr. 1958, 36, 808.

28. Biron, P., M. Chretien, E. Koiw, and J. Genest. Effects of angiotensin infusions on aldosterone and electrolyte excretion in normal subjects and patients with hypertension and adrenocortical disorders. Brit med. J. 1962, 1, 1569.

29. McQueen, E. G., and R. B. I. Morrison. The effects of synthetic angiotensin and noradrenaline on blood 
pressure and renal function. Brit. Heart J. 1961, 23, 1.

30. Peart, W. S., and J. J. Brown. Effect of angiotensin (hypertensin or angiotonin) on urine flow and electrolyte excretion in hypertensive patients. Lancet 1961, 1, 28.

31. Finnerty, F. A., Jr., G. D. Massaro, V. Chupkovich, and J. Tuckman. Evaluation of the pressor, cardiac, and renal hemodynamic properties of angiotensin II in man. Circulat. Res. 1961, 9, 256.

32. Yu, P. N., M. N. Luria, J. K. Finlayson, C. A. Stanfield, H. Constantine, and F. J. Flatley. The effects of angiotensin on pulmonary circulation and ventricular function. Circulat. 1961, 24, 1326.

33. Segel, N., P. Harris, and J. M. Bishop. The effects of synthetic hypertensin on the systemic and pulmonary circulations in man. Clin. Sci. 1961, 20, 49.

34. Johnson, W. P., and R. A. Bruce. Hemodynamic and metabolic effects of angiotensin II during rest and exercise in normal healthy subjects. Amer. Heart. J. 1962, 63, 212.

35. August, J. T., D. H. Nelson, and G. W. Thorn. Response of normal subjects to large amounts of aldosterone. J. clin. Invest. 1958, 37, 1549.

36. Brown, J. J., G. Chapuis, and J. I. S. Robertson. The effect of prolonged intravenous infusion of angiotensin in the rabbit. Clin. Sci. 1964, 26, 165.

37. Dickinson, C. J., and J. R. Lawrence. A slowly developing pressor response to small concentrations of angiotensin. Lancet 1963, 1, 1354.

38. Gross, F., and K. D. Bock. Some contributions to the pharmacology of synthetic angiotensin. Circulation 1962, 25, 193.

39. Howard, J. E. Hypertension as related to renal ischemia. Circulation 1964, 29, 657.

40. Tobian, L. Interrelationship of electrolytes, juxtaglomerular cells and hypertension. Physiol. Rev. 1960, 40, 280.

41. Laragh, J. H. Interrelationships between angiotensin, norepinephrine, epinephrine, aldosterone secretion, and electrolyte metabolism in man. Circulation 1962, 25, 203.

42. Laragh, J. H., and R. P. Ames. Physiology of body water and electrolytes in hepatic disease. Med. Clin. N. Amer. 1963, 47, 587.
43. McManus, J. Medical Diseases of the Kidney. Philadelphia, Lea \& Febiger, 1950.

44. Davis, J. O., P. M. Hartroft, E. O. Titus, C. C. J. Carpenter, C. R. Ayers, and H. E. Spiegel. The role of the renin-angiotensin system in the control of aldosterone secretion. J. clin. Invest. 1962, 41, 378.

45. Davis, J. O., J. Urquhart, and J. T. Higgins, Jr. Renin, angiotensin and aldosterone in experimental secondary hyperaldosteronism. Canad. med. Ass. J. 1964, 90, 245.

46. Selkurt, E. E. Effect of pulse pressure and mean arterial pressure modification on renal hemodynamics and electrolyte and water excretion. Circulation 1951, 4, 541.

47. Thurau, K., P. Deetjen, and K. Kramer. Hamodynamik des Nierenmarks. II. Mitteilung. Wechselbeziehung zwischen vascularem und tubularem Genenstrom-system bei arteriellen Drucksteigerungen, Wasserdiurese und omsotischer Diurese. Pflügers Arch. ges. Physiol. 1960, 270, 270.

48. Tobian, L., K. Coffee, D. Ferreira, and J. Meuli. The effect of renal perfusion pressure on the active transport of sodium out of distal tubular urine as studied with the "stop-flow" technique (abstract). J. clin. Invest. 1962, 41, 1404.

49. Gornel, D. L., R. G. Lancestremere, S. Papper, and L. H. Lowenstein. Acute changes in renal excretion of water and solute in patients with Laennec's cirrhosis, induced by the administration of the pressor amine, metaraminol. J. clin. Invest. 1962, 41, 594.

50. Vaamonde, C. A., I. N. Sporn, R. G. Lancestremere, J. L. Belsky, and S. Papper. Augmented natriuretic response to acute sodium infusion after blood pressure elevation with metaraminol in normotensive subjects. J. clin. Invest. 1964, 43, 496.

51. Borst, J. G. G., and A. Borst-de-Geus. Hypertension explained by Starling's theory of circulatory homœstasis. Lancet 1963, 1, 677.

52. Relman, A. S., W. K. Stewart, and W. B. Schwartz. A study of the adjustments to sodium- and waterretaining hormones in normal subjects (abstract). J. clin. Invest. 1958, 37, 924. 